Heiligers, P.J.M., Hingstman, L.

Career preferences and the work-family balance in medicine: gender differences among medical specialists.

Social Science \& Medicine: 50, 2000, nr. 9, p. 1235-1246

\begin{tabular}{|c|c|}
\hline Postprint Version & 1.0 \\
\hline Journal website & http://dx.doi.org \\
\hline Pubmed link & $\begin{array}{l}\text { http://www.ncbi.nlm.nih.gov/entrez/query.fcgi?db=pubmed\&cmd=Retrieve\&dop } \\
\mathrm{t}=\text { Abstract\&list_uids=10728844\&query_hl=12\&itool=pubmed_docsum }\end{array}$ \\
\hline DOI & 10.1016/S0277-9536(99)00363-9 \\
\hline
\end{tabular}

* Corresponding author. Tel.: +31-30-272-9762, +31-2729700; fax: +31-30-272-9729.

E-mail address: p.heiligers@nivel.nl (Ph.J.M. Heiligers).

\title{
Career preferences and the work: family balance in medicine: gender differences among medical specialists
}

\author{
PhIL J.M. HEILIGERS ${ }^{\mathrm{A}, \mathrm{B},}{ }^{*}$, L. HINGSTMAN ${ }^{\mathrm{A}}$ \\ a Netherlands Institute of Primary Health Care, P.O. Box 1568, 3500 BN Utrecht, The Netherlands \\ b Department of Social and Organizational Psychology, Utrecht University, Utrecht, The Netherlands
}

\begin{abstract}
In this article career preferences of medical specialists in the Netherlands are analysed, based on a survey among the members of medical associations of five specialties. Four different career preferences were offered, each of which implied a possible variation in working hours. A questionnaire was sent to a random selected group of working specialists in general practice, internal medicine, anaesthesiology, ophthalmology and psychiatry. Logistic regressions were used to predict career preferences. Besides individual characteristics, work and home domain characteristics were taken into the analysis. Not surprisingly, the preference for career change in respect of working hours is higher among full-time MDs, especially women, than among part-time workers. In contradiction to what was expected, home domain characteristics did not predict a parttime preference for female, but for male MDs. One home domain characteristic, children's age, did predict the male part-time preference. Further gender differences were found in respect of the fit between actual and preferred working hours (A/P-fit). The majority of male MDs with a full-time preference had achieved an A/P-fit, whereas significantly less female MDs achieved their preferences. It was found that hospital-bound specialists are less positive towards part-time careers than other specialists. Furthermore, the change of working hours would imply a reduction in FTE for all specialties, if all preferences were met. Especially in hospital-bound specialisms it was not confirmed that the reduction in FTE would be low; this was found only in respect of interns. It may be concluded that individual preferences in career paths are very diverse. Personnel policy in medical specialties, especially in hospitals, will have to cope with changes in traditional vertical and age-related career paths. Flexible careers related to home domain determinants or other activities will reinforce a life cycle approach, in which the centrality of work is decreasing.
\end{abstract}

\section{INTRODUCTION}

The work of medical specialists is characterized by long working hours and high demands for quality and continuity of care. These demanding characteristics are expressed in the professional standards specialists set themselves and their colleagues (Leemeijer, 1991; Floor, 1993; Noordenbos and Winants, 1994). However, in the 1990s the centrality of work in the lives of doctors in the Netherlands 
Heiligers, P.J.M., Hingstman, L.

Career preferences and the work-family balance in medicine: gender differences among medical specialists. Social Science \& Medicine: 50, 2000, nr. 9, p. 1235-1246

is perceived to be decreasing (Noordenbos and Winants, 1994; Heymans and Du Moulin, 1996).

Reasons for this development related to the need for reduced working hours can be mentioned. First, women form an increasing percentage of the medical workforce and various studies of women's career paths in medicine have shown that women tend to work fewer hours per week than men (Wakeford and Warren, 1989; Medical Manpower Standing Advisory Committee, 1992; Heiligers et al., 1997). Since 199250 to $60 \%$ of all medical students in the Netherlands have been female and the same development is found in other countries. In the UK women made up about $50 \%$ of the intake to medical school early in the 1990s (Uhlenberg and Cooney, 1990; Redman et al., 1994) in Australia $35 \%$ to $50 \%$ of medical graduates were women in the decade before 1990 (Uhlenberg and Cooney, 1990) and in the USA the proportion of female students has been over 30\% (Wakeford and Warren, 1989). However, among working medical specialists women are still a minority in the Netherlands. Secondly, an increasing number of the younger male specialists-in-training also want to reduce the traditional investment of 50 to $60 \mathrm{~h}$ a week (Dijkstra, 1992; Heymans and Du Moulin, 1996; Keizer, 1996).

This article will focus on preferred career plans of full-time and part-time practitioners in five different specialties in the Netherlands: psychiatrists, ophthalmologists, anaesthesiologists, specialists in internal medicine and general practitioners. The distinction between part-time and full-time working is based on regular working hours, excluding extra duties or hours 'on call'. Career studies traditionally focus on the fit or negotiation between individuals and organizations or work environments (Betz et al., 1989). Specifically, concentration has been on the succession of jobs, vertical mobility or formally organized career paths. However, initial career theories and models have been largely built on male models of success and work. With large numbers of women entering and leaving the workforce at different ages, new patterns are emerging (Dalton, 1989). The most important reason for this more integrated perspective is based on women's wish to balance work and family responsibilities (Ferrier et al., 1989; Wakeford and Warren, 1989; Noordenbos and Winants, 1994; Redman et al., 1994; Royal College of Physicians, 1994). One of the dominant topics is their requests for part-time arrangements or reduced work loads. In the medical world gender-based differences in career paths have become a topical issue recently. In the Netherlands system of medical care most medical specialists are working in a hospital setting, but usually not employed by the hospital. They are self-employed working together with colleagues of the same specialty. As independent entrepreneurs they offer their professional services to one or more hospitals. Working part-time in the hospital in addition to private practice is financially not attractive. So, most medical specialists are working full-time if they work in a hospital setting. An exceptional position is taken by a small proportion psychiatrists and ophthalmologists, who are working in private practices. Furthermore, most general practitioners in the Netherlands work in private practices. Only a relative small proportion of GPs are employed in the private practices of colleagues or in health centers. Two specific specialisms are performed in public services: prevention and advisory care for children and medical officers in companies. These two types of specialism are not involved in this study.

This article will focus on gender differences in determinants for preferred career paths and the fit between actual and preferred career paths among medical specialists (MDs). What are preferred working hours at different stages in their careers and what determinants in the home and work domains influence those preferences? The underlying idea is that individual choice is directed by the work: family-balance: not only by organizational and work domain arguments, but also by home domain aspects (Zedeck, 1992; Frone et al., 1997; Van Schie, 1997; Van Vianen et al., 1997). The home domain aspects are based on theories of socialization and gender-identity (Reichel and Muchinsky, 1985; Fassinger, 1990), in addition to workload and responsibilities in the home domain. Work domain aspects imply structural or organizational standards (Glass and Camarigg, 1991) and professional codes expressing the culture of the work setting (e.g. hospitals) (Noordenbos and Winants, 1994; Heymans and Du Moulin, 1996), which can differ within distinguished types of specialism.

The central question addressed is: What characteristics of the home domain and the work domain predict preferences in career plans of medical specialists and what are the consequences at the level of specialties?

Four specific questions will be examined: 
Heiligers, P.J.M., Hingstman, L.

Career preferences and the work-family balance in medicine: gender differences among medical specialists.

Social Science \& Medicine: 50, 2000, nr. 9, p. 1235-1246

(1) What gender differences can be found between actual and preferred career plans in respect of working hours?

(2) What characteristics of home domain and work domain predict career preferences for male and female medical specialists (MDs)?

(3) To what extent can a fit between actual and preferred working hours be found?

(4) What are the effects of individual preferences in working hours at the level of the specialties?

\section{Home domain and individual characteristics}

\section{Socialization and gender identity}

Home domain characteristics which are determinants in the planning of working hours are related to individual choices relating to the costs and benefits in life.

Firstly, socialization processes influence professional aspirations, on the one hand, and the role of spouse and parent, on the other hand. Generally, on the basis of socialization male specialists may experience a greater urge to acquire status and income than female specialists (Wakeford and Warren, 1989; Noordenbos and Winants, 1994). Secondly, our gender role/identity, the balance of masculine or feminine characteristics, was still found, during the 1980s to influence career aspirations (Reichel and Muchinsky, 1985; Fassinger, 1990). In the Netherlands medical specialisms are male dominated professions. Approximately $78 \%$ of the GP's and $81 \%$ of medical specialists are male (Van Velden and Hingstman, 1998). It is obvious that women who reach the position of medical specialist have already broken traditional patterns of gendered work division. They know that they have entered a profession that is largely male dominated. However, on the basis of traditional role patterns, it can be expected that female specialists will be more aware of competitive aspirations in the home domain and therefore be more strongly motivated to prefer a part-time job than male specialists. But, at the same time it is found that in general in the Netherlands the division of child care tasks between men and women is changing. In the last two decades (1975: 1995) women tend to spend weekly four hours less in care tasks and men's investments raised with three hours (Van der Lippe, 1997). Especially, highly educated men who have children are motivated to work part-time and take their share in child care at home (Van Praag and Niphuis-Nell, 1997). It was found that 60 to $70 \%$ of male specialists working part-time were motivated for a part-time job by their wish to spend more time on family tasks (Heiligers et al., 1997). It is to be expected that male specialists who have chosen to work part-time will not differ from female doctors concerning career preferences, because they have chosen a nonstereotyped gender role.

Hypothesis 1a. Among specialists working part-time no gender differences in career focus will be found.

Hypothesis 1b. Full-time working female specialists are more likely to prefer a part-time career focus than fulltime working male specialists.

\section{Workload at home}

Working part-time can be considered as a positive choice (Glass and Camarigg, 1991). Reduced working hours are necessary to prevent work overload and stress. Specific stages in family responsibilities will increase the workload at home, but the time spent on tasks in the home domain also depends on the level of sources at home, especially in respect of childcare assistance. In a comparison among physicians in Australia, the USA, the UK and Sweden, it was found that for female physicians, marriage and child-rearing were clearly associated with a reduction in hours worked, while for men the effects of marriage and children were the opposite (Uhlenberg and Cooney, 1990). A combination of socialization, gender role/identity and workload at home can most likely be expected to affect women's career preferences.

Hypothesis 2a. A part-time focus in career plans of female specialists will be influenced by home domain characteristics. 


\section{Work domain: structural and cultural influence}

\section{Type of specialism}

The profession of the medical specialist is characterized by a high degree of responsibility as regards professional output and standards: a high quality of health care and services. Those standards of quality and continuity of care are translated in long working hours (Noordenbos and Winants, 1994; Heiligers et al., 1997). As regards the structural setting in the Netherlands, professional standards are also an integral part of the organization of work within hospitals: a five-day weekly schedule in addition to evening, night and weekend duties. Since those standards have been traditionally maintained by male specialists it may be expected that most male specialists prefer a full-time focus, which will be influenced by work domain characteristics.

Hypothesis 2b. A full-time focus in the career plans of male specialists will be influenced by work domain characteristics.

\section{A/P-fit: the fit between actual and preferred working hours}

\section{Gender differences}

Preferred career plans express intentions about the most desirable career path. In this study four different career preferences were posed, based on the idea that a growing number of medical specialists was interested in career choices which offered the option of other activities, especially home domain responsibilities, in addition to the professional role. Broadly speaking two variants are distinguished. On the one hand, career paths which were implicitly full-time: a full-time focus career. On the other hand, career paths characterized by a reduction of working hours during the greater part of the working life: a part-time focus career. Within each career focus, two possible preferences can be chosen.

Since the discussion about reduced working hours has only recently started in the Netherlands, it may be expected that a high proportion of specialists who prefer a part-time focus, actually work full-time. In short, the proportion of specialists with 'no fit' between actual and preferred [A/P] working hours can be expected to be higher than those who have managed a fit between their intentional and actual working hours. Among those who prefer a full-time investment, it can be expected that most of them have required an A/P-fit.

Hypothesis 3a. The A/P-fit is low among medical specialists with a part-time career focus. The A/Pfit is high among medical specialists with a full-time career focus.

For female specialists a high A/P-fit relating to a part-time focus career may be expected. But, female physicians working full-time may be expected to prefer a reduction of working hours, consequently the A/P-fit will be low. We expect the opposite situation for male specialists. In keeping with their high commitment to traditional standards on working hours, the A/P-fit for full-time focus careers will be high among male specialists. But we can also expect a preference for a reduction in working hours among male MDs, because long working hours mean a high workload.

Hypothesis 3b. The A/P-fit in a part-time career focus is high among female specialists. The A/P-fit in part-time career focus is low among male specialists.

Hypothesis 3c. The A/P-fit in full-time career focus is high among male specialists. The A/P-fit in full-time career focus is low among female specialists.

\section{Consequences at the level of specialties}

Individual choices of medical specialists can be traced to consequences for the entire specialty. Based on traditional standards in the Netherlands the effects of changing preferences will be fewer in hospital settings. So, it may be expected that, in hospitals, most doctors will work full-time, but consequently 
Heiligers, P.J.M., Hingstman, L.

Career preferences and the work-family balance in medicine: gender differences among medical specialists. Social Science \& Medicine: 50, 2000, nr. 9, p. 1235-1246

the A/P-fit in hospital settings will be low. Furthermore, beliefs about working part-time can be expected to be most negative in hospital settings.

Hypothesis 4. A less positive orientation as regards working part-time, a low A/P-fit and a low FTEreduction on the level of the specialism will be found in hospital-bound specialisms.

\section{METHOD}

\section{Sample}

Five groups of medical specialties in the Netherlands were selected for participation in this study: psychiatrists, ophthalmologists, anaesthesiologists, specialists in internal medicine and general practitioners. A stratified random sample was drawn from the members of the medical association of those five different specialties. These specialties were selected to cover a variety of specialties, more specifically in respect of the number of female doctors. Assuming that women will be more likely to choose a part-time job, the proportion of female respondents was raised in order to be sure of enough part-time respondents. A stratified random sample of male and female MDs was drawn. To determine the sample size of both strata the following formula was used [24]:

$$
n=\frac{4 p q}{(4 p q / \mathrm{N})+b^{2}}
$$

where, $n$ is the estimation of sample size; $N$ is the population; $p$ is the estimation of percentage of parttime respondents; $q$ is the estimation of percentage of full-time respondents; $b$ is the reliability rate.

In order to have enough part-time respondents for the female population a $p$ of $50 \%$ (or $p=0,5 ; q=$ $0,5)$ was used. And for the male population, in which a small proportion of part-time MDs was expected, it was decided to use a $p$ of $10 \%$ (or $p=0,1 ; q=0,9$ ). Actually, the proportion of women within the five groups of medical specialties varied from 17 to $27 \%$. Response rates varied from 63 to $74 \%$ and the genders did not differ significantly.

The population concerns working specialists, not juniors or trainees. Due to the long lasting training programme most MDs are about $35 \mathrm{yr}$ old when they start their career as a specialist.

\section{Procedure}

A questionnaire was sent to working specialists in five different specialties. Logistic regressions were used to predict career preferences and three clusters of variables were used in the analysis. Cluster 1 covers the individual or socio-biographical characteristics of respondents: age and gender. In cluster 2 home domain characteristics are included in the analysis: having a partner and/or children, age of the youngest child and child care assistance from a partner or from others outside the family. Finally, in cluster 3 the work domain characteristics are gathered: the number of hours worked (in FTE) and the type of specialism.

\section{Measures}

\section{Full-time and part-time work: FTE and hours worked}

In the survey, detailed questions were posed on working hours, family situation and career preferences. All physicians were questioned about the average hours they worked weekly. A problem concerning the measurement of working hours is that a distinction should be made between the formal time worked, expressed in full-time equivalents (FTE) per week, and the actual working hours. The formal time worked concerns the official agreements in contracts or appointments with colleagues. However, in medicine, in several specialties working hours of 55 to $60 \mathrm{~h}$ weekly on average are accepted as a normal pattern. Hence, both figures were asked for and related to each other in order to be able to compare average investment of part-timers and full-timers. Another problem is that a fulltime investment is changing. For decades it used to be $40 \mathrm{~h}$. To avoid this problematic variation in hours we used formal FTE for the division between part-timers and full-timers. Part-timers were defined as those working less than 1.0 FTE. 


\section{Work domain and home domain}

Two characteristics of the work domain were included in the analyses. Firstly, the actual working hours weekly: FTE (full-time equivalents). On the one hand, the actual working hours can fit into the preferred career plan, on the other hand there can be `no fit' between actual hours worked and preferred career. Secondly the type of specialism is included in the analyses. The type of specialism can be an indication for structural and/or cultural barriers to a preferred career choice.

On the basis of earlier research (Frone et al., 1997; Van Emmerik and Hermkens, 1997), the most relevant home domain characteristics are family situation (partner and/or children), the age of the youngest child and the amount of childcare assistance: from a caring partner at home or others outside the family.

\section{Preferred careers: part-time and full-time focus}

As mentioned before, career plans are operationalized here in terms of preferred working times adjusted to various life stages. In those preferences work and home domain aspects are weighted. Recently, for men, home domain aspirations have been increasing (Redman et al., 1994), whereas for women the work domain is becoming a more dominant aspect in life. Several research projects reveal that specialists working in a hospital setting have many problems in achieving home domain aspirations, although differences are mentioned between specialties (Redman et al., 1994; Heiligers et al., 1997; Keizer, 1997).

In summary, individual preferences, organizational policy and cultural beliefs are all determinants in the choice of a career path. The emphasis on the home and work domain aspirations will be different in individual choices. In order to create sufficient differentiation options in both types of aspiration, four specific types of career paths were mentioned. All specialists were asked: 'What type of career path would you prefer for yourself? (Please choose the career path which is nearest to your preference).' First, they could choose a part-time career for their entire working lives. This type of career will be chosen by doctors who wish to plan other activities in their lives in addition to their professional tasks as a specialist. The second career had a full-time start of five years, meant for building up an independent position as a specialist, followed by a reduction of working hours to parttime participation in order to sustain other activities outside the professional setting. The third career plan was characterized by full-time participation during the whole career. This includes doctors with a high level of work domain aspiration. The fourth career started with five years of part-time participation, meant to combine home and work domain tasks when the family is young, followed by full-time participation with a greater emphasis on work domain aspirations. The first two types of career plan were characterized by a part-time focus and the two latter had a full-time focus.

\section{Part-time orientation}

The measure of part-time orientation was constructed for this study. Part-time orientation was measured by asking for opinions about part-time jobs in medicine, especially in the doctor's own specialism. Specialists were questioned about the consequences of working part-time for cooperation and team-work (2 items), consequences for the organization (3 items) and for individual careers (2 items). They were also asked about the impact of working part-time on the quality and continuity of care (2 items) and 1 item was about the acceptability of the present proportion of doctors working part- and full-time in their specialism. Responses were put into a ten-item scale. The internal consistency is sufficiently high for all specialisms (Cronbach's a $>0.70$ ).

\section{Respondents}

In all specialties full-timers were a majority ( $>55 \%)$, but the largest proportion were found in specialties which can be performed in hospital settings only: anaesthesiologists (84\%) and specialists in internal medicine (87\%). As expected, we also found a majority of male physicians in all specialties. Less than $20 \%$ of all specialists experienced support from the organization (hospitals or others) for a part-time career. Age differed significantly between part-time (average: $43 \mathrm{yr}$ ) and fulltime workers (average: $46 \mathrm{yr}$ ), but this difference was mainly found between part-time and full-time female specialists (respectively 40 and $43 \mathrm{yr}$ on the average). As regards the family situation, male specialists working full-time were the most likely to have a partner and children, but among the female 
population the opposite was the case. The majority of female doctors with a partner and/or with children worked part-time. Female physicians working full-time were significantly more often single and childless (60\%) than female colleagues working part-time. Furthermore, more specialists working part-time than fulltime had at least one child aged below 5, whereas more MDs working full-time had children above the age of 13 . Most specialists working full-time (85\%) had child care assistance from a partner, whereas MDs working part-time were significantly less supported by a partner (45\%). This difference is found for both women and men, although a high percentage of men working part-time was also supported by a partner (78\%).

Surprisingly, more than half the specialists responding preferred a part-time focus in their career (Fig. 1). In respect of gender differences relatively more men than women preferred a full-time focus. Nevertheless there was also quite a high preference for a part-time focus among male MDs (44\%). In comparison with male MDs more female doctors preferred working part-time during their whole career. Furthermore it was found that $70 \%$ of all MDs with a preference for part-time work were under 46, whereas among MDs with full-time preferences there were only $45 \%$ under 46 . MDs with a parttime preference had significantly fewer family-ties (partner and/or children) than fulltime focused MDs. As regards the type of specialism, only specialists in internal medicine differed significantly in their preferences: $74 \%$ preferred full-time work.

\section{[ FIGURE 1 ]}

\section{Analyses}

In order to analyse predictive characteristics in work and home domains in respect of the four different career preferences, logistic regressions were used. Four clusters were introduced into the analyses. Cluster 1 relates to individual characteristics: gender and age with the reference category of $>65$ yr. Cluster 2 consisted of home domain characteristics concerning family stage: having a partner and or children and the age-category of the youngest child. The independent variables include partner ( $0=$ no, $1=$ yes), a dummy variable for the children's age, age of youngest child $0-4(0=$ no, $1=$ yes), age of youngest child 5-12 $(0=$ no, yes $=1)$, age of youngest child 13-18 $\mathrm{yr}(0=$ no, yes $=1)$ and having no children is the reference category.

Cluster 3 also relates to the home domain: the amount of child care assistance, which might reduce family time and leave more time for professional work as a specialist. The independent variables in this cluster are child care assistance from partner $(0=$ no, $1=$ yes $)$ and child care assistance from others outside the family $(0=$ no, $1=$ yes $)$.

Cluster 4 concerns the characteristics of different types of specialty and the number of working hours in FTE. The independent variables include each clinical specialty and being a general practitioner is the reference category.

\section{Results}

The first question focused on gender differences in actual and preferred career focus among MDs. It was found that, generally, doctors working part-time preferred to keep a part-time focus in their career (Table 1).

\section{[ TABLE 1 ]}

This tendency was found relatively more often among female MDs working part-time than among part-time male workers. Among psychiatrists, ophthalmologists and specialists in internal medicine almost one third of MDs actually working part-time preferred a full-time focus in their careers. This preference is significantly higher among male psychiatrists and ophthalmologists in comparison with female doctors in these specialties. So, hypothesis 1a, stating that no gender differences will be found among MDs working part-time was not confirmed for all specialties.

Generally the wish to change working hours was higher among MDs working full-time (Table 1) than among part-time workers. In particular, a high proportion of female MDs working full-time preferred a part-time focus. This was found for more than half the female full-time population in all specialties, except for general practitioners. Nevertheless, a relatively high proportion $(>40 \%)$ of male MDs working full-time also preferred a part-time focus. Among ophthalmologists more than half the 
full-time male population had a preference for part-time. Among clinical specialists interns and anaesthesiologists- working full-time the genders differed significantly in part-time preference. In each specialty a majority of the female population (71 and 64\% respectively) preferred a part-time focus to their career, although among male MDs in these two specialties $44 \%$ also preferred a part-time focus. Consequently, hypothesis $1 \mathrm{~b}$ was confirmed for these two hospital-bound specialties, meaning that female MDs working full-time are more likely to prefer a part-time focus than male MDs working full-time.

The second question concerned the home domain and work domain characteristics predicting career preferences of female and male MDs. General practitioners are the reference group in the analysis. The position and preferences of general practitioners were highly comparable with psychiatrists. Separate analyses of the female population did not confirm hypothesis 2a, which stated that part-time preferences of female specialists will be predicted by home domain characteristics (Table 2).

\section{[ TABLE 2 ]}

It was found that career-long part-time work was preferred by young female specialists. A full-time start followed by a time reduction after five years was preferred by women working full-time, especially anaesthesiologists. In contrast to female MDs, home domain characteristics predicted a parttime focus career for male MDs. A full-time start followed by a reduction of working hours after five years was preferred by male MDs with a youngest child in the age between 5-12. This career preference was less likely if male MDs had a partner who took all the responsibilities for childcare at home.

Hypothesis $2 b$ was partly confirmed. It stated that a full-time preference of male MDs will be predicted by work domain characteristics. As regards the type of specialty, a lifetime full-time career was related positively to anaesthesiology and not to psychiatry among male MDs. A part-time start followed by a full-time career after 5 yr is highly preferred by psychiatrists, but not by specialists in internal diseases. Furthermore, home domain characteristics also predict the full-time preferences of male MDs. A part-time start followed by a full-time career after $5 \mathrm{yr}$ is preferred by male MDs whose youngest child is under 5 . A lifetime fulltime career was preferred by male MDs who had a partner at home taking care of the children and this preference was less likely if they had young children ( $<5 \mathrm{yr})$. Neither work-, nor home-domain characteristics predicted a full-time preference for female MDs, except that full-time employment already predicted a full-time preference.

The third question in this article focuses on the Fit between actual and preferred working-hours (Fig. 2).

\section{[ FIGURE 2 ]}

Hypothesis 3a about all MDs was confirmed. The A/P-fit of MDs with a part-time focus was not very low: $45 \%$ had an A/P-fit, which means that they have already achieved their preference for a part-time focus. The A/P-fit of MDs with a full-time focus was high as predicted: $86 \%$ of all MDs were in line with their preference for a full-time career.

A significant difference in A/P-fit of part-time focus careers was found between female and male MDs (TValue: 19.85; $p<0.001$ ). So, hypothesis $3 \mathrm{~b}$ was also confirmed. Among female MDs the A/Pfit in part-time focus was high: $81 \%$ of female MDs had achieved their part-time focus preference. The A/P-fit in part-time focus among male MDs was low (26\%).

Finally, the last hypothesis (3c) on A/P-fit was also confirmed. The A/P-fit for full-time focus careers was significantly different for female and male MDs (Tvalue 11.18; $p<0.001$ ). The A/P-fit of fulltime focus careers was high among male specialists: $91 \%$ had realized a full-time career as preferred. Among female MDs the A/P-fit of a fulltime focus was not very low: $49 \%$ of female MDs who preferred a full-time career achieved it.

The last question focused on the effects of individual working time preferences at the level of the specialties. It was stated that in hospital-bound specialties a low proportion of MDs would be found with a positive orientation towards working part-time. This part of hypothesis 4 was confirmed: only $46 \%$ of the anaesthesiologists and $41 \%$ of interns were positive, whereas larger proportions of other specialties had this positive attitude (Table 3). 


\section{[ TABLE 3 ]}

The A/P-fit for both types of career focus was high in all specialties ( $>50 \%$, except the full-time focus of Hypothesis $2 b$ was partly confirmed. It stated that a full-time preference of male MDs will be predicted by work domain characteristics. As regards the type of specialty, a lifetime full-time career was related positively to anaesthesiology and not to psychiatry among male MDs. A part-time start followed by a full-time career after $5 \mathrm{yr}$ is highly preferred by psychiatrists, but not by specialists in internal diseases. Furthermore, home domain characteristics also predict the full-time preferences of male MDs. A part-time start followed by a full-time career after $5 \mathrm{yr}$ is preferred by male MDs whose youngest child is under 5 . A lifetime fulltime career was preferred by male MDs who had a partner at home taking care of the children and this preference was less likely if they had young children $(<5 \mathrm{yr})$. Neither work-, nor home-domain characteristics predicted a full-time preference for female MDs, except that full-time employment already predicted a full-time preference.

The third question in this article focuses on the Fit between actual and preferred working-hours (Fig. 2).

Hypothesis 3a about all MDs was confirmed. The A/P-fit of MDs with a part-time focus was not very low: $45 \%$ had an A/P-fit, which means that they have already achieved their preference for a part-time focus. The A/P-fit of MDs with a full-time focus was high as predicted: $86 \%$ of all MDs were in line with their preference for a full-time career.

A significant difference in A/P-fit of part-time focus careers was found between female and male MDs (TValue: $19.85 ; p<0.001$ ). So, hypothesis $3 b$ was also confirmed. Among female MDs the A/Pfit in part-time focus was high: $81 \%$ of female MDs had achieved their part-time focus preference. The A/P-fit in part-time focus among male MDs was low (26\%).

Finally, the last hypothesis (3c) on A/P-fit was also confirmed. The A/P-fit for full-time focus careers was significantly different for female and male MDs (Tvalue 11.18; $p<0.001$ ). The A/P-fit of fulltime focus careers was high among male specialists: $91 \%$ had realized a full-time career as preferred. Among female MDs the A/P-fit of a fulltime focus was not very low: $49 \%$ of female MDs who preferred a full-time career achieved it.

The last question focused on the effects of individual working time preferences at the level of the specialties. It was stated that in hospital-bound specialties a low proportion of MDs would be found with a positive orientation towards working part-time. This part of hypothesis 4 was confirmed: only $46 \%$ of the anaesthesiologists and $41 \%$ of interns were positive, whereas larger proportions of other specialties had this positive attitude (Table 3 ).

The A/P-fit for both types of career focus was high in all specialties ( $>50 \%$, except the full-time focus of ophtalmologists: $46 \%$ ) and it differed significantly. The highest Fit-proportion was found among part-time preferences in all five specialties. Consequently, the hypothesis (4) that a low A/P-fit would be found among hospital-bound specialties was not confirmed.

Finally, it was not surprising that the average change in working hours in all specialties would be a reduction in FTE, if all preferences for working hours were met. The proportion of MDs who preferred a reduction of working hours was larger than those who preferred to extend their working hours weekly (Fig. 2). The hypothesis (4) that the reduction in FTE on the average would be low in hospital specialties was only confirmed with respect of interns (ÿ0.01 FTE, Table 3).

\section{Discussion}

An important finding was that more than $50 \%$ of all specialists preferred a part-time focus in their career. From these results, it can be concluded that a large proportion of MDs feel the need for a reduction in working hours. Furthermore, this need to reduce hours in the work domain is not restricted to female doctors.

In first instance, the expectations concerning preferred changes in career seem to be confirmed. Most MDs working part-time are not interested in changing their career focus, although this stability in parttime focus is mostly found among women. In contrast to the stable focus among MDs working parttime a high proportion of MDs working full-time, especially female MDs, would prefer reduction in hours. However, this general conclusion should be more specific. Concerning male specialists, a high proportion of male MDs working fulltime ( $>40 \%$ ) would also prefer a part-time career focus. So, it can be concluded that among male specialists the centrality of the work domain is less strong than was 
expected in terms of the dominant standards of dedication and availability. The dominant part-time preference for men means starting with a full-time position and changing after five years towards parttime work. Separate analysis of the male population showed that male MDs preferring this type of part-time focus are influenced by home domain aspects. A second specific finding concerning male MDs is about male specialists who prefer a part-time start, followed by a full-time career. This career is preferred by male MDs if their youngest child is under 5 . These men focus temporarily on investment in the home domain, but prefer to extend their activities in the work domain after five years. Only a small proportion of female MDs are interested in this type of career choice. This finding is contradictory to what is often expected. It is assumed that women want to extend working hours when their children grow older (Noordenbos, 1997). Furthermore, it is remarkable that the preference by female MDs working full-time for reducing their working hours is not predicted by home domain characteristics. A possible interpretation could be that female MDs prefer working part-time above a full-time investment, regardless of their actual family circumstances. In terms of this argument it can be concluded that the centrality of work is less strong among female specialists than male MDs. On the other hand, female MDs have to cope with male standards and organizational rules, which are not open to discussion. So, the part-time preference of full-time female MDs could also be interpreted as a reaction to their minority position in medicine. Another explanation for the result that among full-time working women the home domain did not predict their views on reducing working hours might be found in the measurement of the home domain. It is mainly operationalized in the context of the nuclear family, especially concentrated on child care tasks. A wider measure of household tasks (shopping, cleaning) and care of parents might have been more adequate.

Finally, age differences are found: as expected young MDs -male as well as female- prefer part-time careers, whereas older MDs -mostly men- prefer a full-time focus. So, time reduction is a new and 'young' phenomenon for MDs, in which young MDs initiate changes in traditional standards and attitudes.

In clinical specialties only practised in hospitals (anaesthesiology and internal medicine), a full-time career focus is the dominant preference. Furthermore, only 20\% of all MDs in clinical settings gave any support to working part-time. So, firstly we can conclude that in hospitals personnel policy, as far as it concerns physicians, is not focussed on a more flexible working hour structure. Secondly, standards accepting long working hours seem to bring about a system which selects MDs who are willing to accept the existing organizational setting. Consequently, female MDs in the hospital setting are also more often full-time. And it is not surprising that about $60 \%$ of these women working fulltime have no children.

If the preferred time reduction achieves a break through, it will be necessary to change personnel policy and the organizational time structure in hospitals and other health organizations. Furthermore, individual preferences in respect of time reduction are very diverse, which would require an increasing degree of flexibility in organizations (Kluwer et al., 1997). Future human resource policy should focus on optimal efficiency towards the use of available capacities (Hall and Mirvis, 1995). Another consequence of reduction in working hours is the necessity of increasing the intake of medical students.

Furthermore, personnel policy will also have to cope with changes in the traditional vertical career paths. Flexible career paths related to home domain determinants or other activities outside work will be less traditionally age-related and vertical. If home domain determinants are also important for male MDs in their career preferences, the distinction between stereotypical male and female career paths could become out of date. Perhaps the concept of career path is not appropriate and should be changed into life cycle path (Noordenbos, 1997). The future trend in working patterns can be expected to be related to the life cycle including family stages and individual diversity in preferences. The most dominant characteristic of future life cycle plans will be flexibility focusing on individuals balancing between work, family and maybe other activities.

If these changes in career policy were implemented widely in health care organizations, female as well as male students would have the opportunity to choose a specialty without the barriers of demanding working hours. We may conclude the centrality of work already is decreasing, not only in the lives of female MDs, but also for male specialists. Home domain aspects have influenced also men's preferences in career focus. Consequently, in the lives of MDs, the meaning of work and standards of professionalism in medicine will change. 
Heiligers, P.J.M., Hingstman, L.

Career preferences and the work-family balance in medicine: gender differences among medical specialists. Social Science \& Medicine: 50, 2000, nr. 9, p. 1235-1246

Future research on this topic could be more specifically focused on the consequences of flexibility in health organizations. In this study, work and organizational characteristics are not specified. In following projects the aspects of work conditions, work satisfaction and workload should be given more attention. Furthermore, in future the measure of home domain should be extended to other activities like cleaning and shopping. The measurement was concentrated on home tasks in the nuclear family, which might have influenced the outcomes in this study.

Another important approach in line with this study is the evaluation of organizational settings (e.g. hospitals) which have implemented flexible working hours in their organizational structure. Evaluation designs focused on diverse types of flexibility can contribute to a high degree of efficiency and an adequate person: organization-fit. 
Heiligers, P.J.M., Hingstman, L.

Career preferences and the work-family balance in medicine: gender differences among medical specialists.

Social Science \& Medicine: 50, 2000, nr. 9, p. 1235-1246

\section{TABLES AND FIGURES}
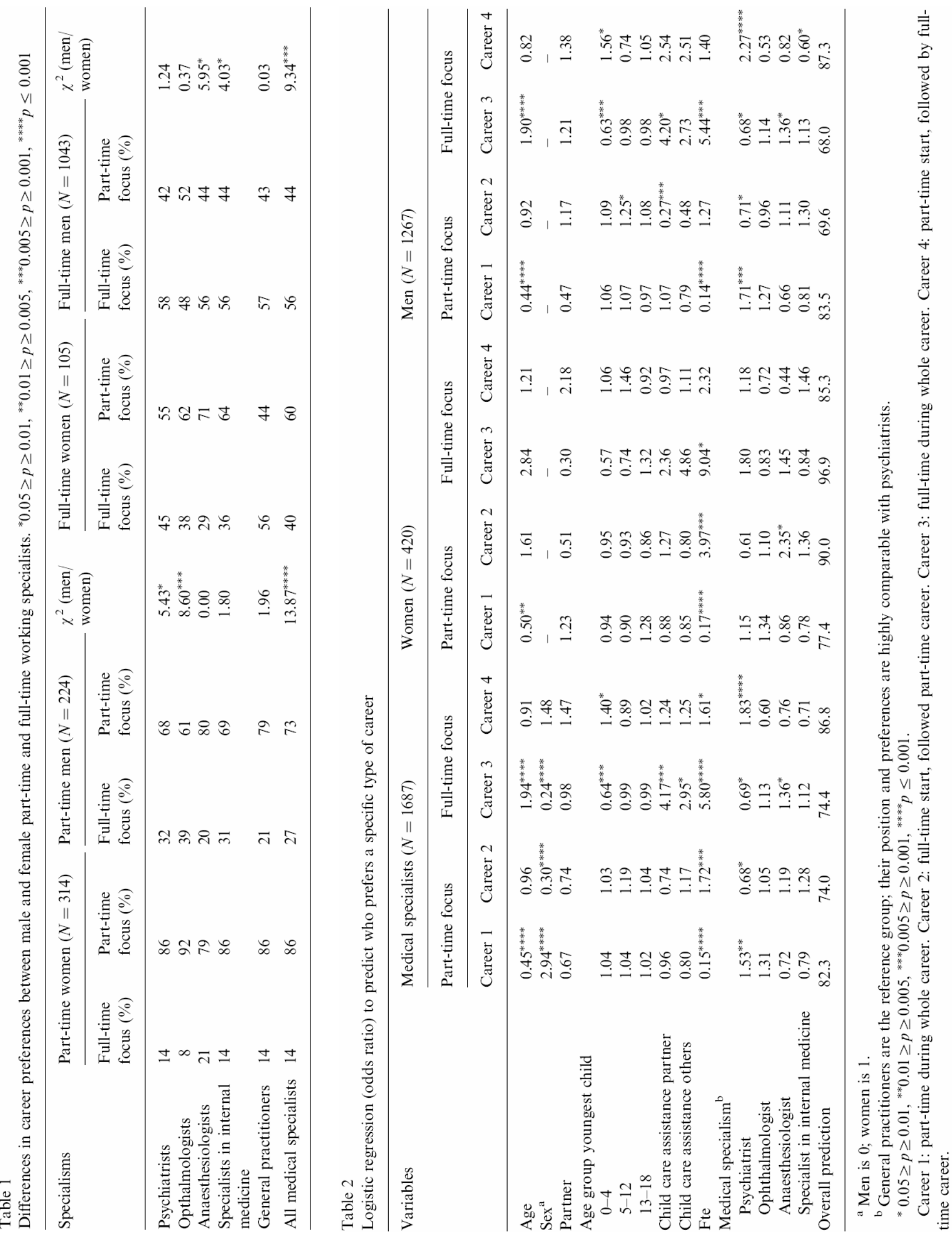
Heiligers, P.J.M., Hingstman, L.

Career preferences and the work-family balance in medicine: gender differences among medical specialists.

Social Science \& Medicine: 50, 2000, nr. 9, p. 1235-1246

Table 3

Positive part-time orientation, the A/P-fit ${ }^{\mathrm{a}}$ and average level of preferred change in Fte in each specialism

\begin{tabular}{|c|c|c|c|c|c|}
\hline \multirow[t]{2}{*}{ Specialists } & \multirow{2}{*}{$\begin{array}{l}\text { Positive orientation } \\
\text { towards part-time working } \\
(\%)^{\mathrm{b}}\end{array}$} & \multicolumn{2}{|l|}{$\begin{array}{l}\text { A/P-fit } \\
(\%)^{\mathrm{a}}\end{array}$} & \multirow[t]{2}{*}{$\chi^{2}$} & \multirow[t]{2}{*}{ Fte-change } \\
\hline & & Full-time focus & Part-time focus & & \\
\hline Psychiatrists & 59 & 57 & 78 & $33.55^{* * * *}$ & $-0.06 \mathrm{fte}$ \\
\hline Anaesthesiologists & 46 & 52 & 80 & $12.65^{* * * *}$ & $-0.04 \mathrm{fte}$ \\
\hline Specialists in internal medicine & 41 & 54 & 78 & $15.20^{* * * *}$ & $-0.01 \mathrm{fte}$ \\
\hline Ophtalmologists & 56 & 46 & 77 & $8.68^{* * * *}$ & $-0.02 \mathrm{fte}$ \\
\hline General practitioners & 58 & 57 & 83 & $112.07^{* * * *}$ & $-0.06 \mathrm{fte}$ \\
\hline
\end{tabular}

${ }^{\mathrm{a}}$ Fit between the actual and preferred working time focus.

${ }^{\mathrm{b}}$ Measured by a ten item-scale (Cronbach's $\alpha>0.70$ ).

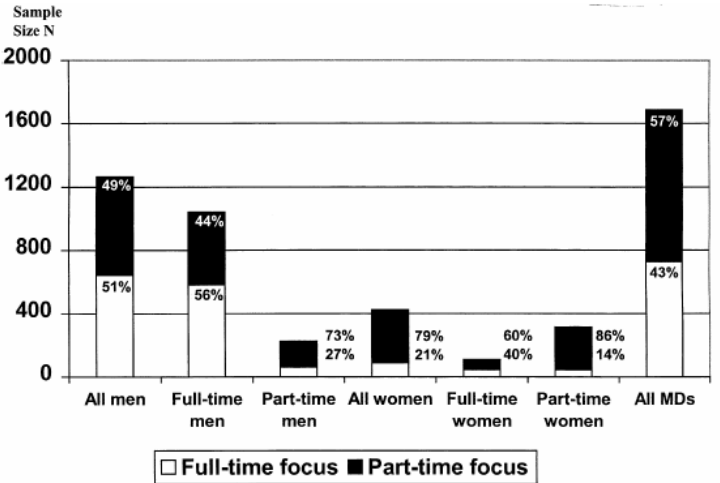

Fig. 1. Preferences in career planning; gender differences in full-time and part-time focus (MDs).

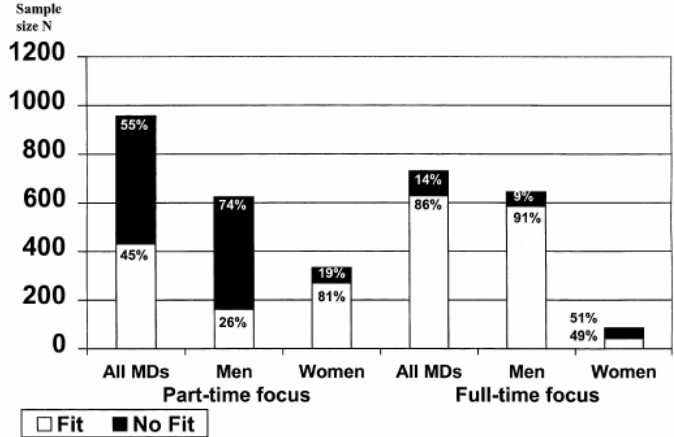

Fig. 2. A/P-fit of male and female specialists with part-time and full-time career focus. A/P-fit: fit between actual and preferred career focus (part-time and full-time focus).

\section{REFERENCES}

Betz, N.E., Fitzgerald, L.F., Hill, R.E., 1989. Trait-factor Theories. In-Arthur, M.B., Hall, D.T., Lawrence, B.S. (Eds.), Handbook of Career Theory. Cambridge University Press, Cambridge, New York, Melbourne, pp. 26-40.

Dalton, G.W., 1989. Developmental Views of Careers in Organizations. In-Arthur, M.B., Hall, D.T., Lawrence, B.S. (Eds.), Handbook of Career Theory. Cambridge University Press, Cambridge, New York, Melbourne, pp. 89-109.

Dijkstra, T.M., 1992. Strijd om Tijd. Een onderzoek naar meningen en wensen van basisartsen met betrekking tot hun beroeps- en privé leven (Struggle for Time. Research on opinions and wishes of trainees in medicine, concerning work and private life). KNMG (Royal Dutch Medical Association) and Utrecht University, Women's studies, Utrecht.

Fassinger, R.E., 1990. Causal models of career choice in two samples of college women. Journal of Vocational Behaviour 36, 225-248.

Ferrier, B.M., Cohen, M., Woodward, Ch.A., 1989. Men and women choose different careers in medicine-causes and consequences. Can. Fam. Physician 35, 1265-1270.

Floor, E., 1993. Deeltijd in strijd met continuïteit? ( Part-time working in conflict with continuity?). NHI.(Netherlands Institute for General Practitioners, Utrecht.

Frone, M.R., Yardley, J.K., Markel, K.S., 1997. Developing and testing an Integrative Model of the Work-Family Interface. Journal of Vocational Behaviour 50, 145-167.

Glass, J., Camarigg, V., 1991. Gender, parenthood and jobfamily compatability. American Journal of Sociology 98 (1), 131-151.

Hall, D.T., Mirvis, P.H., 1995. The new career contact-developing the whole person at midlife and beyond. Journal of Vocational Behaviour 47, 269-289.

Heiligers, Ph.J.M., Hingstman, L., Marrée, J.T.C., 1997. Inventarisatie deeltijd werken onder artsen (Inventory part-time work in medicine). NIVEL, Utrecht.

Heymans, R., Du Moulin, M., 1996. From training grades to career grades (Van basisarts tot medisch specialist (M/V)). RL (University of Limburg), Maastricht. 
Heiligers, P.J.M., Hingstman, L.

Career preferences and the work-family balance in medicine: gender differences among medical specialists.

Social Science \& Medicine: 50, 2000, nr. 9, p. 1235-1246

Keizer, M., 1996. Differences between male and female medical specialists in work- and family situation (Verschillen tussen mannelijke en vrouwelijke specialisten in arbeids- en privé situatie), Tijdschrift voor Arbeidsvraagstukken (Journal for Labour Issues), 12(2), 186-199.

Keizer, M.E., 1997. De dokter spreekt-professionaliteit, gender en uitsluiting in medische specialismen ( Doctor in Discourse-Professionalism, Gender and Exclusion in Medicine). Eburon, Delft.

Kluwer, E.S., Boers, S.A., Heesink, J.A.M., van de Vliert, E., 1997. Rolconflict bij tweeverdieners-de invloed van een 'zorgvriendelijke' werkomgeving. Gedrag en Organisatie (Journal of Behaviour and Organization), 10, 223-241.

Leemeijer, M., 1991. The profession of physicians should become more female-oriented (Het artsenberoep moet vrouwvriendelijker worden), Tijdschrift voor Politiek en Gezondheid (Journal of Politics and Health), 18-20.

Medical Manpower Standing Advisory Committee, 1992. Planning the medical workforce-first report. London-Department of Health (Campbell Report).

Noordenbos, G., Winants, Y., 1994. Feiten en fricties. Sekseasymmetrieën in zorgsystemen (Facts and frictions. Gender-asymmetries in care systems). Uniprint, University of Limburg, Maastricht.

Noordenbos, G., 1997. Feminisation of medicine-threat or challenge? (Feminisering van de geneeskunde-bedreiging of uitdaging?), Women's studies in Medicine (Vrouwenstudies geneeskunde), Universiteit Maastricht (unpublished).

Redman, S., Saltman, D., Straton, J., Young, B., Paul, C., 1994. Determinants of career choices among women and men medical students and interns. Medical Education 28, 361-371.

Reichel, L.S., Muchinsky, P.M., 1985. Life-history and developmental antecedents of female vocational preferences. Journal of Career Assessment 3, 21-34.

Royal College of Physicians, 1994. Part-time work in specialist medicine. Chameleon Press, London.

Uhlenberg, P., Cooney, T.M., 1990. Research Note. Male and female physicians-family and career comparisons. Social Science \& Medecine 30 (3), 373-378.

Van Emmerik, IJ.H., Hermkens, P.L.J., 1997. Flexibilization of labour and possibilities for working parttime (Flexibilisering van de arbeid en de mogelijkheden om part-time te werken). Paper for NSVMarktdag, Utrecht.

Van der Lippe, T., 1997. The division of unpaid labour, 1975-1995 (De verdeling van onbetaalde arbeid, 1995- 1995). In-Niphuis-Nell, M. (Ed.), Social Atlas of Women. 4. The division of unpaid labour, 1975-1995 (Sociale Atlas van de vrouw. 4. Veranderingen in de primaire leefsfeer) , Cahier 141. SCP/VUGA, Rijswijk/Den Haag, pp. 117- 158.

Van Praag, C.S., Niphuis-Nell, M. (Eds.), 1997. The Family Report (Het gezinsrapport). SCP/VUGA, Rijswijk/Den Haag (Cahier 143).

Van Schie, E.C.M. 1997. Career aspirations of men and women before entering the labour market (Loopbaanaspiraties van mannen en vrouwen voor het betreden van de arbeidsmarkt), Gedrag en Organisatie (Journal of Behaviour and Organization), 10(5), 286-299.

Van Velden, L., Hingstman, L., 1998. Behoefteramingen medisch specialisten en huisartsen (19961998) (Manpower analyses in medical specialisms and general practice, 1996-1998). NIVEL, Utrecht.

Van Vianen, A.E.M., van den Heuvel, H., van Schie E.C.M. 1997. Career policy corresponding with the lifecycle (Het afstemmen van een loopbaanbeleid op de levensloop), Gedrag en Organisatie (Journal of Behaviour and Organization), 10(4), 212-222.

Wakeford, R.E., Warren, V.J., 1989. Women doctors' career choice and commitment to medicineimplications for general practice. Journal of the Royal College of General Practitioners 39, 91-95.

Zedeck, S., 1992. Introduction-exploring the domain of work and family concerns. In-Zedeck, S. (Ed.), Work, Families and Organizations. Jossey-Bass Publishers, San Franscisco, pp. 1-32. 